infection in the United States and Asia (A2 virus).

FROM: Specter M. Flu epidemic hits millions in Ukraine and Russia. New York Times. December 28, 1995:A7.

\section{Ehrlichiosis Outbreak Among Golfers}

Ehrlichiosis due to Ehrlichia chaffeensis usually occurs sporadically or in small clusters; the principal vector is the Lone Star tick. An outbreak of ehrlichiosis was reported recently among members of a golf-oriented retirement community (community A) in Tennessee. The community is densely wooded and borders a wildlifemanagement area where deer are numerous. Investigation revealed 11 cases of symptomatic ehrlichiosis, 10 of which were in community A. Of 311 surveyed residents in community A, $12.5 \%$ had serologic evidence of past $E$ chaffeensis infection, as compared to $3.3 \%$ of 92 residents in another golf-oriented community 20 miles away (community B). The risk of infection was associated with tick bites, expo- sure to wildlife, and golfers who had retrieved lost golf balls from the rough. Persons who never used insect repellent were more likely to have had infection than persons who did. In community A, thousands of Lone Star ticks were found; in community B, only three ticks were found.

Human ehrlichiosis, one of several recently emerging infections, was first described in the United States in 1987, with more than 400 cases reported since that time. The researchers concluded that the high rate of $E$ chaffeensis infection in community A resulted from its proximity to a wildlife reserve; when outdoor activities are common and concentrations of ticks are high, outbreaks of arthropodborne zoonoses can be anticipated.

FROM: Standaert SM, Dawson JE, Schaffner W, et al. Ehrlichiosis in a golf-oriented retirement community. $N$ Engl J Med 1995;333:420-425.

Additional news items in this issue: Smoke Tubes Not Reliable for Negative-Pressure Monitoring, page 91; DOT Exempts Cultures and Stocks From Strict Packaging, page 107; Meningococcal Carriage Linked to Campus Bar, page 128.

\title{
Classified Marketplace
}

\section{EMPLOYMENT OPPORTUNITIES}

THE CHAIR OF THE DIVISION OF QUALITY HEALTH CARE must be a Board-Certified Internist with an advanced degree in Public Health and Board Certified in Infectious Diseases. In addition, the candidate will have had at least 2 years' fellowship training in an established program of Hospital Epidemiology apart from training in Infectious Diseases. The candidate must have some record of success in securing funding for research in the field of infection control and clinical epidemiology. Evidence for success in having papers published in the peer-reviewed literature is essential. Particular emphasis will be in identifying a candidate who has had success in organizing multi-institutional epidemiological studies. Other qualifications include expertise in teaching and clinical care. Send letter of application and curriculum vitae by 3/15/96 to: Todd Gehr, MD, Associate Professor, Division of Nephrology, PO Box 980160, Richmond, Virginia 23298. Virginia Commonwealth University is an Equal Opportunity/Affirmative Action Employer. Women, minorities, and persons with disabilities are encouraged to apply.

HOSPITAL EPIDEMIOLOGIST. The Dept. of Medicine at the University of Mississippi School of Medicine seeks physician BC/BE in Infectious Diseases to share responsibilities for Hospital Epidemiology with the current fulltime physician. This physician would oversee activities at 376-bed Veterans Affairs Hospital and 593-bed University Hospital as well as several smaller facilities. Position is tenure track with responsibilities including teaching of residents and medical students and attending in general internal medicine and Infectious Disease consultation. A strong interest in research in nosocomial infection and experience with molecular typing techniques is considered mandatory. For further information, contact R.L. Nolan, MD (601) 984-5556. Div of ID, Dept of Medicine, University of Mississippi Medical Center, 2500 North State Street, Jackson, MS 39216. Equal Opportunity Employer, M/F/D/V.

HOSPITAL EPIDEMIOLOGY FELLOWSHIP-Position available July, 1996 at UT Health Science Center, San Antonio, Department of Medicine/ID. One year fellowship for MD with previous ID training to study hospital epidemiology. Fellow will learn principles of surveillance, control of nosocomial infection, biostatistics and epidemiology methods, DNA typing, and antibiotic utilization. Applicants send letter of interest and CV to: Dr. Jan Patterson, Dept. of Medicine/ID, University of Texas Health Science Center, 7703 Floyd Curl Drive, San Antonio, TX 78284-7881, FAX: 210/616-3905. UTHSCSA is an equal opportunity/affirmative action employer.

\section{SERVICES}

FOR YOUR CONVENIENCE you can fax your ad for placement in INFECTION CONTROL AND HOSPITAL EPIDEMIOLOGY 609-853-5991, atten: Classified Advertising Department or call 1-800-257-8290, in New Jersey 609-848-1000. 